\title{
Bond strengths of one-step self-etch adhesives to laser-irradiated and bur-cut dentin after water storage and thermocycling.
}

\author{
Akin, Gulsah E ; Herguner-Siso, Seyda ; Özcan, Mutlu ; Ozel-Bektas, Ozden ; Akin, Hakan
}

\begin{abstract}
OBJECTIVE: The objectives of this study were to evaluate the microtensile bond strength ( $\mu$ TBS) of one-step self-etch adhesive systems to Er:YAG laser-irradiated and bur-cut dentin after water storage and thermocycling. BACKGROUND DATA: The Er:YAG laser is a promising alternative method for cavity preparation; however, no study has compared the effect of laser irradiation and aging procedures on the adhesion of one-step self-etch adhesives to dentin. METHODS: Seventy-two third molars were selected and randomly divided according to cavity preparation method (Er:YAG laser and bur-cut). One-step self-etch adhesive systems (Clearfil S(3) Bond, AdheSE One and Adper Easy One) were used to bond the composite to dentin. Following the adhesive procedure, the specimens were subdivided according to aging conditions ( $24 \mathrm{~h}$ in water control [C], 6 months of water storage [WS] and 10.000 thermocycles [TC]). The $\mu$ TBS was determined in a universal testing machine. Three-way ANOVA, independent samples t test, and post-hoc comparisons test $(\alpha=0.05)$ were performed on all data. Results: There was no statistical difference in $\mu$ TBS between Er:YAG laser-irradiated and bur-cut dentin $(p>0.05)$. Similarly, no significant difference was found in $\mu$ TBS between $C$, WS, and TC specimens $(p>0.05)$. Moreover, Clearfil S(3) Bond presented the highest $\mu$ TBS to dentin in both laser-irradiated and bur-cut cavity preparation methods. CONCLUSIONS: Neither bur-cut nor Er:YAG laser-irradiated dentin was affected by the aging methods used to simulate degradation of the adhesive interface. Er:YAG laser treatment may be used as an alternative cavity preparation method.
\end{abstract}

DOI: https://doi.org/10.1089/pho.2011.3170

Posted at the Zurich Open Repository and Archive, University of Zurich

ZORA URL: https://doi.org/10.5167/uzh-75534

Journal Article

Published Version

Originally published at:

Akin, Gulsah E; Herguner-Siso, Seyda; Özcan, Mutlu; Ozel-Bektas, Ozden; Akin, Hakan (2012). Bond strengths of one-step self-etch adhesives to laser-irradiated and bur-cut dentin after water storage and thermocycling. Photomedicine and Laser Surgery, 30(4):214-221.

DOI: https://doi.org/10.1089/pho.2011.3170 


\title{
Bond Strengths of One-Step Self-Etch Adhesives to Laser-Irradiated and Bur-Cut Dentin After Water Storage and Thermocycling
}

\author{
Gulsah E Akin, D.D.S., Ph.D., ${ }^{1}$ Seyda Herguner-Siso, D.D.S., Ph.D., ${ }^{2}$ Mutlu Ozcan, D.D.S., Ph.D., ${ }^{3}$ \\ Ozden Ozel-Bektas, D.D.S., Ph.D., and Hakan Akin, D.D.S., Ph.D. ${ }^{4}$
}

\begin{abstract}
Objective: The objectives of this study were to evaluate the microtensile bond strength ( $\mu$ TBS) of one-step selfetch adhesive systems to Er:YAG laser-irradiated and bur-cut dentin after water storage and thermocycling. Background data: The Er:YAG laser is a promising alternative method for cavity preparation; however, no study has compared the effect of laser irradiation and aging procedures on the adhesion of one-step self-etch adhesives to dentin. Methods: Seventy-two third molars were selected and randomly divided according to cavity preparation method (Er:YAG laser and bur-cut). One-step self-etch adhesive systems (Clearfil $\mathrm{S}^{3}$ Bond, AdheSE One and Adper Easy One) were used to bond the composite to dentin. Following the adhesive procedure, the specimens were subdivided according to aging conditions $(24 \mathrm{~h}$ in water control $[\mathrm{C}], 6$ months of water storage [WS] and 10.000 thermocycles [TC]). The $\mu$ TBS was determined in a universal testing machine. Three-way ANOVA, independent samples $t$ test, and post-hoc comparisons test $(\alpha=0.05)$ were performed on all data. Results: There was no statistical difference in $\mu \mathrm{TBS}$ between Er:YAG laser-irradiated and bur-cut dentin $(p>0.05)$. Similarly, no significant difference was found in $\mu$ TBS between C, WS, and TC specimens $(p>0.05)$. Moreover, Clearfil $S^{3}$ Bond presented the highest $\mu \mathrm{TBS}$ to dentin in both laser-irradiated and bur-cut cavity preparation methods. Conclusions: Neither bur-cut nor Er:YAG laser-irradiated dentin was affected by the aging methods used to simulate degradation of the adhesive interface. Er:YAG laser treatment may be used as an alternative cavity preparation method.
\end{abstract}

\section{Introduction}

S ELF-ETCHING SYSTEMS IN WHICH the prior etching step is omitted, combine priming and bonding (one-step adhesives), or they may require an additional step (two-step adhesives). ${ }^{1}$ One-step self-etch adhesives not only reduce clinical application time but also lessen the complexity of the technique and risk of making errors during application. ${ }^{2-4}$ The use of one-step self-etch adhesives can prevent discrepancies from occurring between the depth of etching and resin monomer penetration. ${ }^{5}$ In these adhesives, hydrophobic and hydrophilic monomers are mixed together with a high solvent content, such as acetone and ethanol, in order to maintain them in solution. ${ }^{6-8}$ A precursor of these adhesives is a selfetching primer composed of aqueous mixtures of acidic functional monomers, generally phosphoric acid esters or carboxylates, such as 10-methacryloyloxydecyl dihyrogen phosphate (MDP), 4-methacryloxyethyl trimellitic acid (4MET), and 2-methacryloxyethyl phenyl hydrogen phosphate (phenyl-P). ${ }^{9,10}$ In hydrophilic monomers, carboxylic and phosphate groups act as proton donors in the partial demineralization of the smear layer and have the potential to bond ionically with the calcium from residual hydroxyapatite. ${ }^{7}$

The current trend in minimally invasive dentistry involves alternative techniques for dental cavity preparation, such as laser irradiation ${ }^{11-17}$ and aluminum oxide air abrasive. ${ }^{12,18}$ Such approaches replace the invasive technique of using highspeed dental burs. ${ }^{12,17,19}$, Cavity preparation using lasers takes more time than cavity preparation with rotary cutting instruments, but advantages include low noise and vibration and

\footnotetext{
${ }^{1}$ Department of Restorative Dentistry, Cumhuriyet University, Faculty of Dentistry, Sivas, Turkey.

${ }^{2}$ Department of Restorative Dentistry, Bezmialem University, Faculty of Dentistry, Istanbul.

${ }^{3}$ Center for Dental and Oral Medicine, Clinic for Fixed and Removable Prosthodontics and Dental Materials Science, University of Zürich, Dental Materials Unit, Zürich, Switzerland.

${ }^{4}$ Department of Prosthodontics, Cumhuriyet University, Faculty of Dentistry, Sivas, Turkey.
} 
eliminating the need for local anesthesia in most cases. An additional advantage of laser cavity preparation is that a smear layer of debris is not produced on the surface of the prepared cavity. ${ }^{15}$ Among the various laser types used in dentistry, the erbium: yttrium aluminum garnet (Er:YAG) laser is one of the most highly recommended. Its strong reputation results from the fact that its $2.94 \mu \mathrm{m}$ wavelength emission coincides with the main absorption peaks of water $(\sim 3.0 \mu \mathrm{m})$ and hydroxyapatite, thus resulting in good absorption in all biologic tissues, including enamel, dentin, and cementum. ${ }^{12,13,15,17}$ Furthermore, the increase in temperature under Er:YAG laser irradiation to the pulp and tissues comes within acceptable limits $\left(<3^{\circ} \mathrm{C}\right)$ with water spray for cooling. ${ }^{16,20}$ Cooling also prevents cracking of enamel and dentin. ${ }^{17}$

The evaluation of bonding durability is important, as the bond between the restorative material and the tooth substrate has a significant impact on the clinical success of restoration. ${ }^{5,9}$ In an attempt to mimic the natural aging process of dental restoration, thermocycling protocols and the water storage (WS) of bonded specimens have been suggested as efficient methods to provide in vitro simulation of in vivo conditions. ${ }^{11}$ Thermal cycling simulates the introduction of hot and cold extremes (between $5^{\circ}$ and $55^{\circ} \mathrm{C}$ ) in the oral cavity while showing the relationship of the linear coefficient of thermal expansion between tooth and restorative materi$\mathrm{al}^{21,22}$ On the other hand, in the WS aging procedure, the bonded specimens are stored in fluid at $37^{\circ} \mathrm{C}$ for a specific period, which may vary from a few months up to $4-5$ years, or perhaps longer. Degradation of interface components by hydrolysis of resin or collagen may occur after WS. ${ }^{22,23}$

The Er:YAG laser is a promising alternative method for cavity preparation; however, very little information has been published on the adhesion of one-step self-etch adhesives to the laser-irradiated dentin after aging procedures. Therefore, the objectives of this study were to compare the microtensile bond strengths ( $\mu \mathrm{TBS}$ ) of one-step self-etch adhesives to laser-irradiated and bur-cut dentin after WS and thermocycling. The null hypotheses were as follows: (1) there were no differences in $\mu$ TBS between laser-irradiated and bur-cut dentin; and (2) artificial aging, including WS and thermocycling, decreases the bond strength of the one-step self-etch adhesive systems to dentin.

\section{Methods}

Seventy-two human maxillary third molar teeth that were free of caries, cracks, fractures, and restoration were selected. After extraction, the teeth were cleaned of surface debris and stored in $0.5 \%$ chloramine-T at $4{ }^{\circ} \mathrm{C}$ for $<1$ month. Each tooth was mounted in cold-curing acrylic resin (Meliodent, Bayer Dental Ltd., Newbury, UK). They were then submerged in tap water to reduce any temperature increase caused by the exothermic polymerization reaction of the acrylic resin. While fully hydrated, each third molar was first cut just below the occlusal pit and fissure, perpendicular to the long axis of the tooth, by means of a slow-speed diamond saw (Isomet Low Speed Saw, Buehler Ltd., Lake Bluff, IL). The surface was ground with 600-grit silicon carbide paper (Carbimet Buehler, Buehler Ltd.) under running water for $30 \mathrm{sec}$ to create a smear layer of clinically relevant thickness. The specimens were randomly assigned to two groups according to the cavity preparation methods.

\section{Cavity preparation}

Er:YAG laser irradiation (group I). The laser system used in this study was the Er:YAG laser (Smart 2940D Plus, Deka Laser, Florence, Italy) with a $2.94 \mu \mathrm{m}$ wavelength. Laser energy was delivered in pulse mode with a repetition rate of $10 \mathrm{~Hz}$, energy at $200 \mathrm{~mJ}$, output power of $2 \mathrm{~W}$, and pulse duration of $700 \mu \mathrm{s}$. The time of irradiation was not standardized during cavity preparations. The distance of application was $10 \mathrm{~mm}$, which was standardized by a custom-designed apparatus consisting of two parts: a holder to fix the laser handpiece in such a way that the laser beam was delivered perpendicular to the specimen surface at a constant working distance from the target site, and a semi-adjustable base, upon which an acrylic plate and fragment were attached. Furthermore, an occlusal cavity was prepared with a dimension of $4 \mathrm{~mm} \times 4 \mathrm{~mm}^{2}$ and $2 \mathrm{~mm}$ deep by Er:YAG laser on each tooth. The depth of the cavity was calibrated by measuring with a periodontal probe. Water irrigation at a rate of $5 \mathrm{~mL} / \mathrm{min}$ also was used during lasing of the specimens.

Bur preparation (group II). The cavities were prepared with a high-speed \#1090 fissure diamond bur (Diatech Dental AG, Heerbrugg, Switzerland) under air-water spray coolant at a rate of $5 \mathrm{~mL} / \mathrm{min}$. The cavity was $4 \mathrm{~mm} \times 4 \mathrm{~mm}^{2}$ and $2 \mathrm{~mm}$ deep. New burs were used after every five preparations.

\section{Specimen preparation}

Three different one-step self-etch adhesives-Clearfil $S^{3}$ (Kuraray Medical, Tokyo, Japan), AdheSE One (Ivoclar Vivadent, Schaan, Liechtenstein), and Adper Easy One (3M ESPE, St Paul, MN, USA) - were applied to the cavity. Details regarding the adhesive systems selected, such as manufacturers, composition, application technique, and batch number, are listed in Table 1. The selected manufacturers' recommended hybrid resin composites-Clearfil AP-X (Kuraray Medical, Tokyo, Japan), Tetric N-Ceram (Ivoclar Vivadent, Schaan, Liechtenstein), and Filtek Z250 (3M ESPE, St Paul, MN)-were applied following the incremental technique and light cured for $20 \mathrm{sec}$. All procedures and curing times were performed according to the manufacturers' instructions. Specimens were stored in distilled water at $37^{\circ} \mathrm{C}$ for $24 \mathrm{~h}$ and were divided into three subgroups: control (C), WS, and thermocycles (TC).

\section{Aging procedure}

The specimens retrieved at $24 \mathrm{~h}$ of WS were used as controls. The specimens in the WS groups were aged in distilled water at $37^{\circ} \mathrm{C}$ in a water bath machine (BM 402; Nüve, Ankara, Turkey) for 6 months. The water was changed weekly in order to accelerate the degradation process. The specimens in the TC groups were subjected to thermocycling (10.000 cycles between $5^{\circ}$ and $55^{\circ} \mathrm{C}$ ) (Nova, Nova Ticaret, Konya, Turkey). The dwell time in the water bath was $30 \mathrm{sec}$, and the transfer time was $7 \mathrm{sec}$.

\section{Microtensile testing}

For $\mu$ TBS testing, specimens were serially sectioned perpendicular to the bonding surface using the Isomet saw 
Table 1. Adhesive Systems Used in This Study

\begin{tabular}{|c|c|c|c|c|}
\hline Adhesives & Components & Batch & Application & Manufacturer \\
\hline Clearfil $S^{3}$ & $\begin{array}{l}\text { Bis-GMA, MDP, HEMA, hydrophobic } \\
\text { dimethacrylate, camphorquinone, ethyl } \\
\text { alcohol, silanized colloidal silica, water }\end{array}$ & 41168 & $\begin{array}{l}\text { Scrub } 20 \text { sec, dry for } \\
5 \mathrm{sec} \text {, light cure } 10 \mathrm{sec} .\end{array}$ & Kuraray \\
\hline AdheSE One & $\begin{array}{l}\text { Bis-acrylamide, water, bis(methacrylamide) } \\
\text { dhydrogen phosphate, amino acid } \\
\text { acrylamide, silicon dioxide, catalysts, and } \\
\text { stabilizers }\end{array}$ & L17858 & $\begin{array}{l}\text { Scrub } 30 \mathrm{sec} \text {, strongly } \\
\text { dry, light cure } 10 \mathrm{sec} .\end{array}$ & Ivoclar vivadent \\
\hline $\begin{array}{l}\text { Adper Easy } \\
\text { One }\end{array}$ & $\begin{array}{l}\text { HEMA, Bis-GMA, methacrylated phosphoric } \\
\text { esters, 1,6 hexanediol dimethacrylate, } \\
\text { methacrylate functionalized polyalkenoic acid } \\
\text { (Vitrebond copolymer), finely dispersed } \\
\text { bonded silica filler with } 7 \text { nm primary particle } \\
\text { size, ethanol, water, initiators, based on } \\
\text { camphorquinone, stabilizers }\end{array}$ & 376899 & $\begin{array}{l}\text { Scrub } 20 \mathrm{sec} \text {, dry for } \\
5 \mathrm{sec} \text {, light cure } 10 \mathrm{sec} .\end{array}$ & 3M ESPE \\
\hline
\end{tabular}

Bis-GMA, bisphenol A glycerolate dimethacrylate, MDP, 10-methacryloyloxydecyl dihydrogen phosphate; HEMA, 2-hydroxyethyl methacrylate.

under running water in order to obtain rectangular sticks with a cross-sectional surface area of $\sim 1.0 \mathrm{~mm}^{2}( \pm 0.2 \mathrm{~mm})$. Each stick was attached to a custom jig of a universal testing machine (Lloyd LF Plus; Ametek Inc., Lloyd Instruments, Leicester, UK) using a cyanoacrylate adhesive (Model Repair II Pink, Dentsply-Sankin, Otawara, Japan) and subjected to a tensile force at a crosshead speed of $1 \mathrm{~mm} / \mathrm{min}$ until failure occurred. The fractured sticks were removed from the testing apparatus, and the cross-sectional area at the site of failure was measured to the nearest $0.01 \mathrm{~mm}$ with a digital caliper (Altas 905; Gedore-Altas, Istanbul, Turkey). The $\mu$ TBS was calculated from this measurement and expressed in MPa. Twenty bond strengths of each group were obtained, and the data were analyzed using a three-way ANOVA test. Independent samples $t$ tests and post-hoc comparisons were performed at a 0.05 significance level.

\section{Failure analysis}

The fractured specimens were examined under a stereomicroscope (SMZ 800, Nikon, Tokyo, Japan) at $40 \times$ magnification, to evaluate the fracture pattern. Failure modes were classified into one of three categories: adhesive failure if debonding occurred between resin and dentin; mixed failure if the failure exhibited was partially adhesive and partially cohesive in bonding resin or in hybrid layer; or cohesive failure occurred in resin or in dentin. All observations were conducted by one person. In addition, the fractured surfaces for each group were examined using a scanning electron microscope (SEM, LEO 440, Zeiss, Oberkochen, Germany). Representative specimens were photographed at $5000 \times$ magnification after the $\mu$ TBS test. SEM micrographs of burcut specimens and the Er:YAG laser-irradiated specimens are presented in Figs. 1, 2, and 3.

\section{Results}

Three-way ANOVA tests results for $\mu$ TBS measurements of the groups are summarized in Tables 2 and 3. Analysis of the data revealed that there were no significant differences between the methods when the cavity preparation methods were compared $(p>0.05)$. In general, the bur-cut dentin displayed similar $\mu$ TBS to the laser-irradiated dentin. Clearfil $S^{3}$ Bond presented the highest $\mu \mathrm{TBS}$ to dentin, irrespective of the cavity preparation method used.

$\mu$ TBS results were not affected by either cavity preparation method $(p=0.112$ and $F=2.546)$ or the aging conditions ( $p=0.149$ and $F=1.912$ ), whereas, in the interaction of the factors, the cavity preparation method and aging conditions demonstrated a statistically significant difference $(p<0.001$ and $F=14.236$ ). Ultimately, $\mu$ TBS results were significantly affected by adhesive type $(p<0.001$ and $F=39.33)$. The interaction of the factors cavity preparation method, adhesive type, and aging conditions showed a statistically significant difference in $\mu$ TBS $(p<0.001$ and $F=8.319)$. The bond strength of Clearfil $S^{3}$ Bond was significantly higher than those of Adper Easy One and AdheSE One $(p<0.001)$. Moreover, there was a significantly different $\mu$ TBS between Adper Easy One and AdheSE One $(p=0.008)$.

In comparison to the $C$ group, TC and WS did not decrease the mean $\mu$ TBS of one-step self-etching adhesives $(p=0.894$ and $p=0.148)$. Similarly, no significant differences were found among the $\mu$ TBS results for TC and WS $(p=0.331)$. Modes of failure are presented in Table 4 . The analysis of failure after the microtensile test revealed that the adhesive failure mode was observed in both $C$ and aged groups for both laser-irradiated and bur-cut cavity methods.

At $5000 \times$ magnification, bur-cut dentin was characterized by a quite irregular topography (Fig. 1) and Er:YAG lasertreated surfaces (Figs. 2 and 3) had a similarly distinctive, irregular, and scaly appearance, exhibiting open tubules and absence of a smear layer.

\section{Discussion}

The results obtained in this study clearly demonstrate that the $\mu$ TBS of laser-irradiated dentin was similar to that of burcut dentin, by which the first hypothesis was accepted. The second hypothesis was rejected, because $\mu$ TBS results were not affected by the aging conditions. Contradictory results and conclusions on tensile bond strengths after Er:YAG laser treatment may be found in the literature, because many different experimental setups have been used. Lee et al. ${ }^{16}$ reported that the bur-cut/acid-etched and laser-ablated/ 
FIG. 1. Scanning electron microscope (SEM) photograph of bur-cut dentin surface after microtensile bond strength $(\mu \mathrm{TBS})$ test (original magnification: $\times 5000)$.

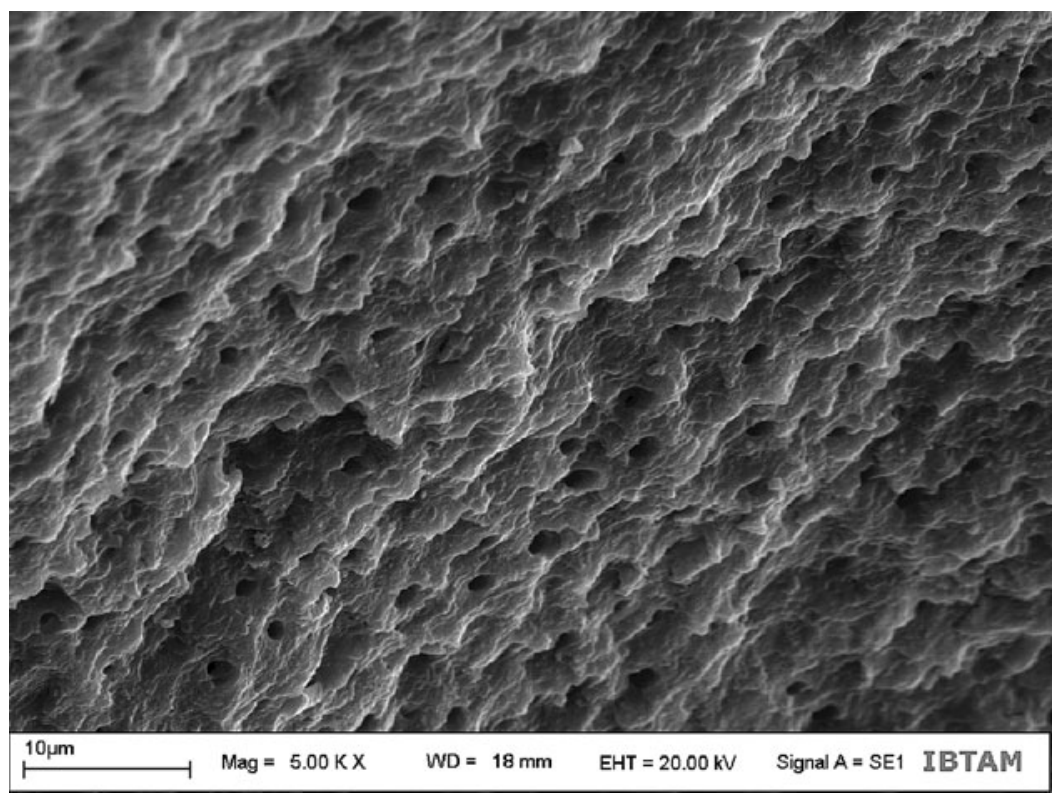

acid-etched groups showed no statistical significance. Furthermore, Souza-Zaroni et al. ${ }^{12}$ demonstrated that Er:YAG laser groups (250 and $300 \mathrm{~mJ}$ ) were not statistically different in $\mu$ TBS from the bur-cut group. The results of the present study were consistent with Lee et al. ${ }^{16}$ and Souza-Zaroni et al. ${ }^{12}$

Also, in alignment with the results of the present study, do Amaral et al. ${ }^{11}$ found that there was no significant difference in $\mu$ TBS between bur-cut and laser-irradiated specimens in WS for $24 \mathrm{~h}$. However, contrary to the results of the present study, do Amaral and colleagues also reported that there were significant differences when the cavity preparation methods were compared. Moreover, Er:YAG laserprepared specimens demonstrated lower $\mu \mathrm{TBS}$ after being stored in water for 6 months with 12,000 TC. In addition, Trajtenberg et al. $^{15}$ demonstrated that Er:YAG laserirradiated and bur-cut dentin had similar $\mu$ TBS when the surfaces were acid etched followed by an etch-and-rinse adhesive. Bur-cut dentin showed higher bond strengths than did laser-irradiated dentin with the use of an experimental self-etching adhesive.

In contrast, De Munck et al. ${ }^{17}$ stated that the two-step selfetch adhesive bonded equally well to lased and to bur-cut enamel, but significantly less effectively to lased than to burcut dentin. Furthermore, Botta et al. ${ }^{14}$ investigated the influence of the cavity preparation and primer application methods on the $\mu$ TBS of the self-etching system. They found that Er:YAG laser-irradiated dentin presented significantly lower $\mu$ TBS than did bur-cut dentin. Moreover, Cardoso et al. $^{19}$ reported that $\mu$ TBS to laser-irradiated dentin was significantly lower than to bur-cut dentin. The results of the present study contradicted those of De Munck et al., ${ }^{17}$ Botta et al., ${ }^{14}$ and Cardoso et al. ${ }^{19}$

FIG. 2. Scanning electron microscope (SEM) photograph of the Er:YAG laser treated dentin surface after microtensile bond strength $(\mu \mathrm{TBS})$ test (original magnification: $\times 5000)$.

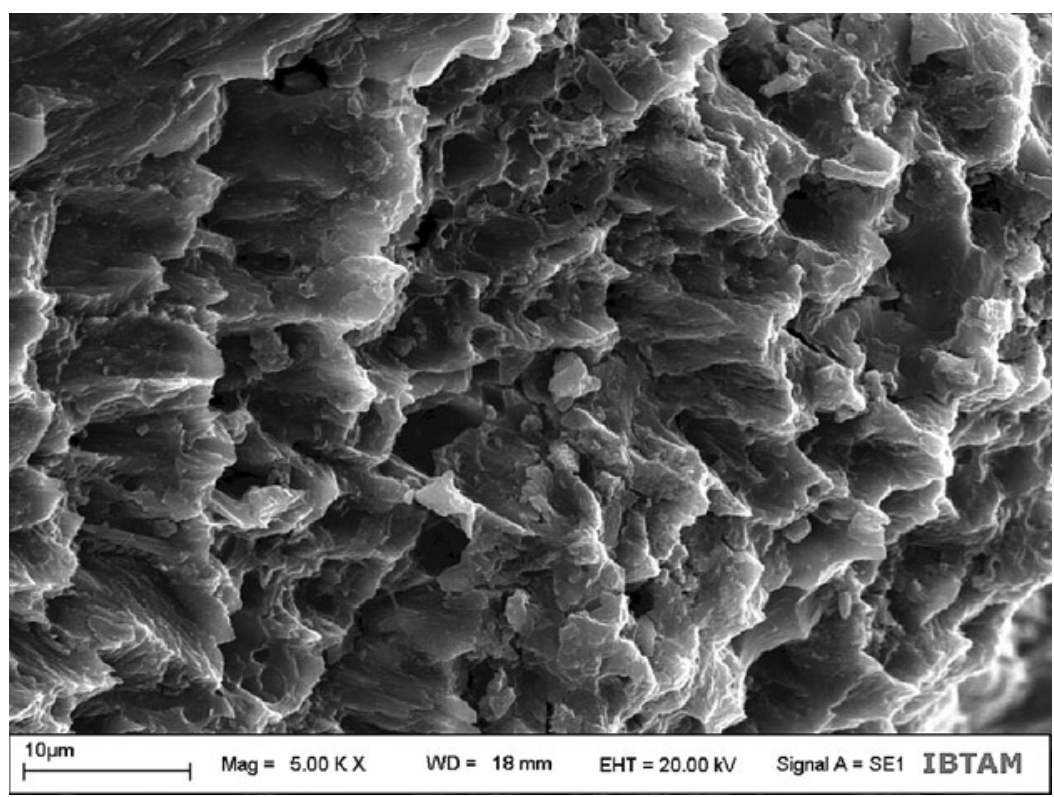




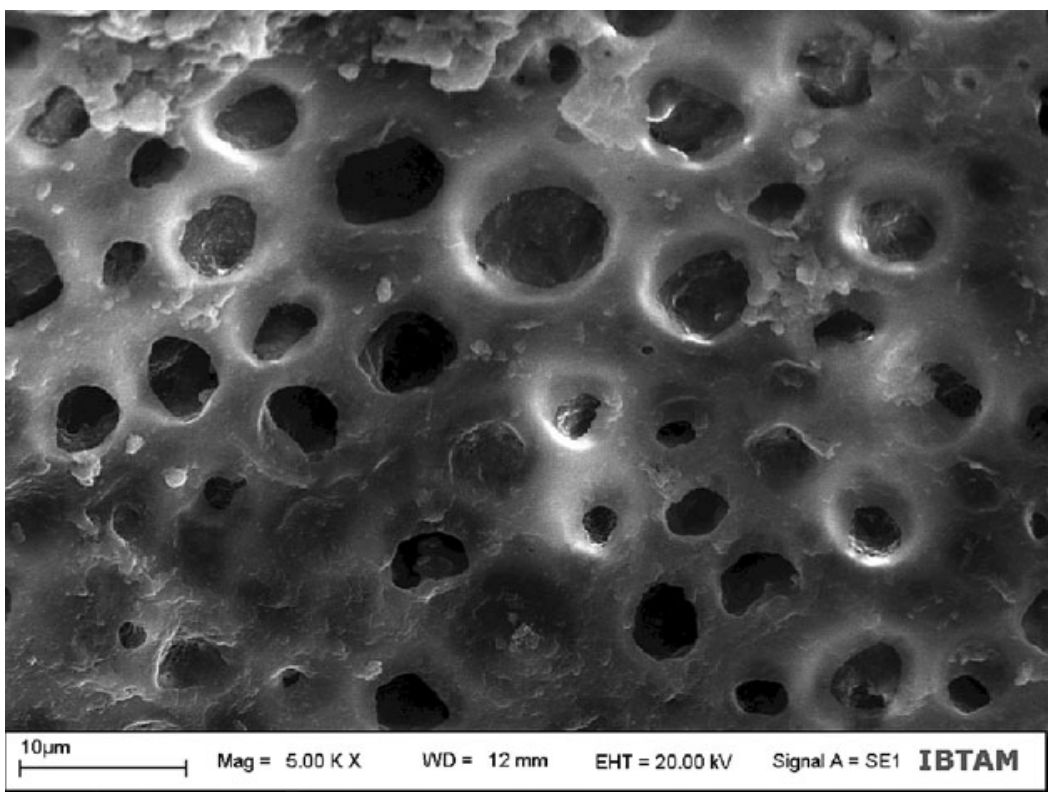

FIG. 3. Scanning electron microscope (SEM) photograph of the Er:YAG laser treated dentin surface after microtensile bond strength $(\mu$ TBS) test (original magnification: $\times 5000$ ).
The mechanism of the laser's cutting effect generally indicated that water droplets produced violent microexpansion after efficiently absorbing the laser energy, which subsequently formed hydrokinetic forces that could quickly ablate the dental hard tissues. ${ }^{16}$ Laser-irradiated dentin reveals a scaly, rough surface, lack of a smear layer, open dentinal tubules, and an ultrastructurally modified intertubular dentin. ${ }^{12}$ The peritubular dentin protruding from the surrounding intertubular dentin possibly resulted from the higher mineral content and the lower water content of peritubular dentin. ${ }^{16}$

No evidence of thermal changes, such as melting or carbonation, which were found in Er:YAG laser irradiation of higher energy, were observed, because laser irradiation was performed in association with water mist. ${ }^{16,19}$ In addition, neither Knoop hardness nor $\mathrm{Ca} / \mathrm{P}$ ratio evaluations on the cavity floor revealed any significant difference between laser and bur treatment. ${ }^{20}$ However, some researchers have asserted that Er:YAG treatment promotes morphological changes in the dentin adhesive interface that may have a relationship to reductions in bond strength. The effects of Er:YAG laser irradiation, such as fusion of the collagen fibrils and restriction of resin diffusion into the subsurface dentin, may result in an adhesive interface with failed areas and gaps in which hydrolytic degradation could be facilitated.
Furthermore, during Er:YAG laser irradiation on dentin, the amount of water is decreased, which later can be partly restored by water uptake. ${ }^{11}$ This reduction in water content during Er:YAG laser irradiation probably decreases diffusion of adhesive resin and elimination of the solvent. ${ }^{11}$ In addition, irregularities of the dentin produced by the laser ablation may prevent a uniform stress distribution at the adhesive interface $^{19}$ and cause a reduction of water. ${ }^{15}$ It was reported that decomposed organic substance in dentin, ${ }^{12}$ microcracks below the hybrid layer, and subsurface damage (which can also exceed the thickness of the hybrid layer) were found in Er:YAG laser-irradiated dentin. ${ }^{17}$ Therefore, the decomposed superficial layer obstructed the infiltration of the self-etching primer, and the primer could not fulfill its function for the superficial layer of Er:YAG laser-irradiated dentin. ${ }^{12}$

Researchers thought that all the surface alterations might affect hybridization and bonding effectiveness, even when laser irradiation is followed by acid etching. A more acidresistant surface could have reduced the etching effectiveness, particularly when using the less acidic self-etch adhesive. ${ }^{17}$ Nevertheless, no significant difference was found in $\mu$ TBS between bur-cut and laser-irradiated dentin after WS and thermocycling in the present study.

Many different experimental setups have been used for Er:YAG laser application and described in the literature. Treatments with very long pulses of up to $1000 \mu$ s resulted in

Table 2. Mean Microtensile Bond Strength (MPa) and SD of Each Adhesive System

\begin{tabular}{|c|c|c|c|c|c|c|}
\hline \multirow{2}{*}{$\begin{array}{l}\text { One-step self-etch } \\
\text { adhesives }\end{array}$} & \multicolumn{2}{|c|}{ Control } & \multicolumn{2}{|c|}{ Thermocycling } & \multicolumn{2}{|c|}{ Water Storage } \\
\hline & Bur-cut & Laser & Bur-cut & Laser & Bur-cut & Laser \\
\hline Clearfil $S^{3}$ Bond & $23.58^{\mathrm{a}, \mathrm{b}, \mathrm{A}}(3.04)$ & $24.77^{\mathrm{b}, \mathrm{A}}(1.54)$ & $24.12^{\mathrm{a}, \mathrm{A}}(3.51)$ & $22.57^{\mathrm{a}, \mathrm{A}}(3.51)$ & $22.87^{\mathrm{a}, \mathrm{A}}(2.89)$ & $24.68^{\mathrm{b}, \mathrm{A}}(2.66)$ \\
\hline AdheSE One & $20.36^{\mathrm{a}, \mathrm{B}}(4.49)$ & $20.92^{\mathrm{a}, \mathrm{d}, \mathrm{B}}(1.98)$ & $23.16^{\mathrm{b}, \mathrm{A}}(2.65)$ & $16.17^{\mathrm{c}, \mathrm{B}}(3.4)$ & $17.99^{\mathrm{a}, \mathrm{B}}(3.87)$ & $21.65^{\mathrm{d}, \mathrm{B}}(4.18)$ \\
\hline Adper Easy One & $20.31^{\mathrm{a}, \mathrm{B}}(3.24)$ & $18.34^{\mathrm{b}, \mathrm{c}}(2.77)$ & $22^{\mathrm{a}, \mathrm{c}, \mathrm{A}}(3.28)$ & $21.43^{\mathrm{a}, \mathrm{c}, \mathrm{A}}(3.54)$ & $23.52^{\mathrm{c}, \mathrm{A}}(4.49)$ & $22.37^{\mathrm{c}, \mathrm{B}}(2.7)$ \\
\hline
\end{tabular}

For each horizontal row: values with small letters indicate no statistically significant difference $(p>0.05)$.

For each vertical column: values with capital letters indicate no statistically significant difference $(p>0.05)$. 
Table 3. Three-Way ANOVA for Microtensile Bond Strength of the Groups

\begin{tabular}{|c|c|c|c|c|c|}
\hline Source & Type III sum of squares & $\mathrm{df}$ & Mean square & $\mathrm{F}$ & Sig. \\
\hline Corrected model & $1915.801^{\mathrm{a}}$ & 17 & 112.694 & 10.330 & 0.000 \\
\hline Intercept & 169809.133 & 1 & 169809.133 & 15565.124 & 0.000 \\
\hline Cavity preparation methods & 27.772 & 1 & 27.772 & 2.546 & 0.112 \\
\hline Adhesives & 858.153 & 2 & 429.076 & 39.330 & 0.000 \\
\hline Aging & 41.726 & 2 & 20.863 & 1.912 & 0.149 \\
\hline Cavity preparation methods * adhesives & 49.705 & 2 & 24.852 & 2.278 & 0.104 \\
\hline Cavity preparation methods * aging & 310.614 & 2 & 155.307 & 14.236 & 0.000 \\
\hline Adhesives * aging & 264.807 & 4 & 66.202 & 6.068 & 0.000 \\
\hline $\begin{array}{l}\text { Cavity preparation methods * } \\
\text { adhesives * aging }\end{array}$ & 363.024 & 4 & 90.756 & 8.319 & 0.000 \\
\hline Error & 3731.080 & 342 & 10.910 & & \\
\hline Total & 175456.014 & 360 & & & \\
\hline Corrected total & 5646.881 & 359 & & & \\
\hline
\end{tabular}

${ }^{\mathrm{a}} \mathrm{R}^{2}=0.339$ (Adjusted $\mathrm{R}^{2}=0.306$ ).

a dentin surface with chemical and morphological characteristics very similar to that obtained with conventional methods; however, with very short pulses (VSP), a strong modification of collagen aliphatic chains was observed. ${ }^{20}$ Therefore, long pulse duration was used in this study. Different levels of Er:YAG laser energy have also been used by researchers. ${ }^{11-15,17,24,25}$ do Amaral et al. ${ }^{24}$ used the Er:YAG laser set at $300 \mathrm{~mJ}$ and $4 \mathrm{~Hz}$ to prepare cavities in the enamel. In another study, do Amaral et al. ${ }^{11}$ performed Er:YAG laser cavity preparation on a dentin surface with output energy at $260 \mathrm{~mJ}$ and repetition rate of $4 \mathrm{~Hz}$. According to De Munck et al. ${ }^{17}$ and Firat et al., ${ }^{25}$ Er:YAG laser settings for dentin ablation were $80 \mathrm{~mJ}$ and $10 \mathrm{~Hz}$.

Trajtenberg et al. ${ }^{15}$ used Er:YAG laser energy settings of $160 \mathrm{~mJ}$ and $10 \mathrm{~Hz}$ for dentin. Souza-Zaroni et al. ${ }^{12}$ and Botta et al. ${ }^{14}$ used the settings at $250 \mathrm{~mJ}$ and $4 \mathrm{~Hz}$. Souza-Zaroni et al. ${ }^{12}$ also used $300 \mathrm{~mJ}$ and $4 \mathrm{~Hz}$ for preparing cavities on dentin. Korkmaz et al. ${ }^{13}$ prepared cavities using an Er:YAG laser set at $200 \mathrm{~mJ}$ and $20 \mathrm{~Hz}$ for dentin substrate. Hence, to determine the laser parameters used in this study, a pilot study was performed. Based on those results, $200 \mathrm{~mJ}, 10 \mathrm{~Hz}$, and $2 \mathrm{~W}$ were selected. For Er:YAG laser application, many different experimental setups have been used and described in the literature, and application of lasers in different parameters such as energy, output power, and pulse duration can affect the results of the studies. Future investigations could focus on which parameters are more suitable for dentin bond strength.

The distance of the laser application was selected based on the previous studies. ${ }^{13,26-28}$ Furthermore, application time was not standardized during cavity preparations. Because it was important to prepare occlusal cavities with specific dimensions of $4 \times 4 \times 2 \mathrm{~mm}$ for each tooth in the present study, and each tooth's hardness or structure varied, cavity preparation time changed. Therefore, the sizes of the cavities were standardized in the present study instead of laser application time.

Reports in the literature show that researchers have evaluated adhesion in Er:YAG laser-irradiated tooth structure by performing bond strength tests after $24 \mathrm{~h}$ of WS without thermocycling. However, only one study evaluated adhesive resin bonding durability in Er:YAG laser cavity preparations after WS and thermocycling. Therefore, aging conditions could not exactly be compared to the literature.

Abdalla et al. ${ }^{23}$ found that after 4 years of indirect WS, the bond strength of each adhesive decreased, but this reduction was not significant. The residual hydroxyapatite around the exposed collagen fibrils remained available for additional chemical interaction with the functional monomers. This bonding mechanism seems to be able to tolerate indirect WS for at least 4 years. However, Frankenberger et al. ${ }^{29}$ reported that after 90 days, bond strengths were stable, whereas, after 2,190 days of WS, a significant loss of bond strength was evident in adhesive systems. Similar to the results of the Frankenberger et al., ${ }^{29}$ Foxton et al. ${ }^{30}$ revealed that bond strengths of the adhesive systems to dentin significantly decreased after 1 year of WS. Ülker et al. ${ }^{31}$ and Asaka et al. ${ }^{32}$ also found that the aging condition of 10.000 thermal cycles was not effective on the $\mu$ TBS of the one-step self-etch adhesive systems.

Table 4. Modes of Failures of Each Adhesive System

\begin{tabular}{|c|c|c|c|c|c|c|c|c|c|c|c|c|c|c|c|c|c|c|c|c|c|c|c|c|}
\hline \multirow[b]{3}{*}{ Adhesive systems } & \multicolumn{8}{|c|}{ Control } & \multicolumn{8}{|c|}{ Thermocycling } & \multicolumn{8}{|c|}{ Water storage } \\
\hline & \multicolumn{4}{|c|}{ Bur-cut } & \multicolumn{4}{|c|}{ Laser } & \multicolumn{4}{|c|}{ Bur-cut } & \multicolumn{4}{|c|}{ Laser } & \multicolumn{4}{|c|}{ Bur-cut } & \multicolumn{4}{|c|}{ Laser } \\
\hline & $a$ & $c$ & $d$ & $m$ & $a$ & $c$ & $d$ & $m$ & $a$ & $c$ & $d$ & $m$ & $a$ & $c$ & $d$ & $m$ & $a$ & $c$ & $d$ & $m$ & $a$ & $c$ & $d$ & $m$ \\
\hline Clearfil $S^{3}$ Bond & 18 & 2 & 0 & 0 & 19 & 0 & 1 & 0 & 13 & 6 & 1 & 0 & 17 & 2 & 0 & 1 & 17 & 1 & 0 & 2 & 18 & 1 & 0 & 1 \\
\hline AdheSE One & 20 & 0 & 0 & 0 & 20 & 0 & 0 & 0 & 16 & 2 & 1 & 1 & 20 & 0 & 0 & 0 & 18 & 2 & 0 & 0 & 17 & 3 & 0 & 0 \\
\hline Adper Easy One & 18 & 2 & 0 & 0 & 19 & 1 & 0 & 0 & 15 & 4 & 0 & 1 & 17 & 1 & 0 & 2 & 19 & 1 & 0 & 0 & 19 & 1 & 0 & 0 \\
\hline
\end{tabular}

a,adhesive; $c$, cohesive in composite; $d$, cohesive in dentin; $\mathrm{m}$, mix. 
Cardoso et al. ${ }^{19}$ revealed that mix failures were frequently observed in the laser-irradiated groups because of the prominent irregularities of laser-irradiated dentin. De Munck et al. ${ }^{17}$ found cohesive fractures in dentin for Er:YAG laser groups; subsurface damage produced by the laser can cause thickness in the hybrid layer. In the present study, an adhesive failure mode was observed.

Future studies should concentrate on the effects of Er:YAG laser irradiation on the bond strength of other restorative materials, with different experimental setups.

\section{Conclusions}

Within the limitations of this study, adhesion of the Er:YAG laser-irradiated dentin was similar to that of the bur-cut dentin. Water storage and thermocycling were found to be ineffective on the $\mu$ TBS of one-step self-etch adhesive systems. Clearfil $\mathrm{S}^{3}$ Bond presented the highest $\mu \mathrm{TBS}$ to dentin, regardless of the cavity preparation method used.

\section{Acknowledgment}

This investigation was supported in part by the Cumhuriyet University Scientific Research Project.

\section{Author Disclosure Statement}

No conflicting financial interests exist.

\section{References}

1. Spreafico, D., Semeraro, S., Mezzanzanica, D., et al. (2006) The effect of the air-blowing step on the technique sensitivity of four different adhesive systems. J. Dent. 34, 237-244.

2. do Amaral, R.C., Stanislawczuk, R., Zander-Grande, C., Michel, M.D., Reis, A., and Loguercio, A.D. (2009). Active application improves the bonding performance of self-etch adhesives to dentin. J. Dent. 37, 82-90.

3. De Munck, J., Van Landuyt, K., Peumans, M., et al. (2005). A critical review of the durability of adhesion to tooth tissue: methods and results. J. Dent. Res. 84, 118-132.

4. Hiraishi, N., Breschi, L., Prati, C., Ferrari, M., Tagami, J., and King, N.M. (2007). Technique sensitivity associated with air-drying of HEMA-free, single-bottle, one-step self-etch adhesives. Dent. Mater. 23, 498-505.

5. Asaka, Y., Amano, S., Rikuta, A., et al. (2007). Influence of thermal cycling on dentin bond strengths of single-step selfetch adhesive systems. Oper. Dent. 32, 73-78.

6. Monticelli, F., Osorio, R., Pisani-Proença, J., and Toledano, M. (2007). Resistance to degradation of resin-dentin bonds using a one-step HEMA-free adhesive. J. Dent. 35, 181-186.

7. Margvelashvili, M., Goracci, C., Beloica, M., Papacchini, F., and Ferrari, M. (2010). In vitro evaluation of bonding effectiveness to dentin of all-in-one adhesives. J. Dent. 38, 106112.

8. Hashimoto, M., Fujita, S., Kaga, M., and Yawaka, Y. (2008). Effect of water on bonding of one-bottle self-etching adhesives. Dent. Mater. J. 27, 172-178.

9. Ozel-Bektas, O., Herguner-Siso, S., and Akin, E.G. (2011). Effect of thermal cycling on microtensile bond strengths of various adhesives to dentin. Cumhuriyet. Dent.J. 14, 12-17.

10. Tsuchiya, H., Tsubota, K., Iwasa, M., Ando, S., Miyazaki, M., and Platt, J.A. (2010). Influence of adhesive application time on enamel bond strength of single-step self-etch adhesive systems. Oper. Dent. 35, 77-83.
11. do Amaral, F.L., Colucci, V., de Souza-Gabriel, A.E., Chinelatti, M.A., Palma-Dibb, R.G., and Corona, S.A. (2008). Adhesion to Er:YAG laser-prepared dentin after long-term water storage and thermocycling. Oper. Dent. 33, 51-58.

12. Souza-Zaroni, W.C., Chinelatti, M.A., Delfino, C.S., Pécora, J.D., Palma-Dibb, R.G., and Corona, S.A. (2008). Adhesion of a self-etching system to dental substrate prepared by Er:YAG laser or air abrasion. J. Biomed. Mater. Res. B. Appl. Biomater. 86B, 321-329.

13. Korkmaz, Y., Ozel, E., Attar, N., Bicer, C.O., and Firatli, E. (2010). Microleakage and scanning electron microscopy evaluation of all-in-one self-etch adhesives and their respective nanocomposites prepared by erbium:yttrium-aluminum-garnet laser and bur. Lasers Med. Sci. 25, 493-502.

14. Botta, S.B., Vieira, S.N., Cordon, R., Marques, M.M., and Matos, A.B. (2009). Can the method of primer application influence adhesion to Er:YAG-laser irradiated dentin? J. Contemp. Dent. Pract. 10, 49-57.

15. Trajtenberg, C.P., Pereira, P.N., and Powers, J.M. (2004). Resin bond strength and micromorphology of human teeth prepared with an Erbium:YAG laser. Am. J. Dent. 17, 331-336.

16. Lee, B.S., Lin, P.Y., Chen, M.H., et al. (2007). Tensile bond strength of Er,Cr:YSGG laser-irradiated human dentin and analysis of dentin-resin interface. Dent. Mater. 23, 570-578.

17. De Munck, J., Van Meerbeek, B., Yudhira, R., Lambrechts, P., and Vanherle, G. (2002). Micro-tensile bond strength of two adhesives to Erbium:YAG-lased vs. bur-cut enamel and dentin. Eur. J. Oral. Sci. 110, 322-329.

18. Malmström, H.S., Chaves, Y., and Moss, M.E. (2003). Patient preference: Conventional rotary handpieces or air abrasion for cavity preparation. Oper. Dent. 28, 667-671.

19. Cardoso, M.V., Coutinho. E., Ermis, R.B., et al. (2008). Influence of Er,Cr:YSGG laser treatment on the microtensile bond strength of adhesives to dentin. J. Adhes. Dent. 10, 25-33.

20. Bader, C., and Krejci, I. (2006). Indications and limitations of Er:YAG laser applications in dentistry. Am. J. Dent. 19, 178186.

21. El Araby, A.M., and Talic, Y.F. (2007). The effect of thermocycling on the adhesion of self-etching adhesives on dental enamel and dentin. J. Contemp. Dent. Pract. 8, 17-24.

22. De Munck, J., Van Landuyt, K., Coutinho, E., et al. (2005). Micro-tensile bond strength of adhesives bonded to class-I cavity-bottom dentin after thermo-cycling. Dent. Mater. 21, 999-1007.

23. Abdalla, A.I., and Feilzer, A.J. (2008). Four-year water degradation of a total-etch and two self-etching adhesives bonded to dentin. J. Dent. 36, 611-617.

24. Amaral, F.L., Colucci, V., Souza-Gabriel, A.E., Chinelatti, M.A., Palma-Dibb, R.G., and Corona, S.A. (2010). Bond durability in erbium:yttrium-aluminum-garnet laser-irradiated enamel. Lasers Med. Sci. 25, 155-163.

25. Firat, E., Gurgan, S., and Gutknecht, N. (2012). Microtensile bond strength of an etch-and-rinse adhesive to enamel and dentin after Er:YAG laser pretreatment with different pulse durations. Lasers Med. Sci. 27, 15-21.

26. Akin, H., Tugut, F., Emine, Akin, G., Guney, U., and Mutaf, B. (2012). Effect of Er:YAG laser application on the shear bond strength and microleakage between resin cements and Y-TZP ceramics. Lasers Med. Sci. 27, 333-338.

27. Malkoc, M.A., Taşdemir, S.T., Ozturk, A.N., Ozturk, B., and Berk, G. (2011). Effects of laser and acid etching and air abrasion on mineral content of dentin. Lasers Med. Sci. 26, 21-27. 
28. Korkmaz, Y., Ozel, E., Attar, N., and Ozge, Bicer, C. (2010). Influence of different conditioning methods on the shear bond strength of novel light-curing nano-ionomer restorative to enamel and dentin. Lasers Med. Sci. 25, 861-866.

29. Frankenberger, R., Strobel, W.O., Lohbauer, U., Kramer, N., and Petschelt, A. (2004). The effect of six years of water storage on resin composite bonding to human dentin. J. Biomed. Mater. Res. B. Appl. Biomater. 69B, 25-32.

30. Foxton, R.M., Melo, L., Stone, D.G., Pilecki, P., Sherriff, M., and Watson, T.F. (2008). Long-term durability of one-step adhesive composite systems to enamel and dentin. Oper. Dent. 33, 651-657.

31. Ülker, M., Özcan, M., Şengün, A., Özer, F., and Belli, S. (2010). Effect of artificial aging regimens on the performance of self-etching adhesives. J. Biomed. Mater. Res. B. Appl. Biomater. 93B, 175-184.

32. Asaka, Y., Yamaguchi, K., Inage, H., et al. (2006). Effect of thermal cycling on bond strengths of single-step self-etch adhesives to bovine dentin. J. Oral. Sci. 48, 63-69.

Address correspondence to: Gulsah Akin

Faculty of Dentistry, Cumhuriyet University, 58140 Sivas

Turkey

E-mail: gulsah_goktolga@hotmail.com 